\title{
Livelihood changes and evolution of upland ethnic communities driven by tourism: a case study in Guizhou Province, southwest China
}

LI Ya-juan",2 (D http://orcid.org/oooo-0oo2-5787-0459; e-mail: yajuan.li@mail.ccnu.edu.cn YU Hu3 (iD http://orcid.org/oooo-ooo3-3159-8183; e-mail: yuhuashd@126.com CHEN Tian3 (iD http://orcid.org/oooo-ooo1-7735-4577; e-mail: chent@igsnrr.ac.cn HU Jing1,2 (D http://orcid.org/oooo-0003-0307-9562; e-mail: huj@mail.ccnu.edu.cn CUI Hai-yang4 (iDhttp://orcid.org/oooo-ooo1-7397-8518; Мe-mail: hosanna2004@163.com 1 The College of Urban \& Environmental Sciences, Central China Normal University, Wuhan 430o79, China 2 Wuhan Branch of China Tourism Academy, Wuhan 430079, China

3 Institute of Geographic Sciences and Natural Resources Research, University of Chinese Academy of Sciences, Beijing 100101, China

4 ASEAN (Association of Southeast Asian Nations) Research Center, Guizhou University, Guiyang 550o25, China

Citation: Li YJ, Yu H, Chen T, et al. (2016) Livelihood changes and evolution of upland ethnic communities driven by tourism: a case study in Guizhou Province, southwest China. Journal of Mountain Science 13(7). DOI: 10.1007/s11629015-3631-6

(C) Science Press and Institute of Mountain Hazards and Environment, CAS and Springer-Verlag Berlin Heidelberg 2016

\begin{abstract}
As an effective livelihood approach to alleviate poverty without rural population migration, ethnic tourism has become the primary choice of economic development in ethnic areas worldwide in addition to traditional livelihood approaches. This article applies the theories of livelihood to study the community evolution driven by tourism livelihood and examine three mountainous tourism communities in different stages of tourist area life cycle. Drawing on the methods of GIS spatial analysis, semi-structured interviews and questionnaires, this article proposes a sustainable livelihood framework for ethnic tourism to explore the evolution of ethnic tourism communities by identifying changes in livelihood assets (natural, financial, social, cultural and human capitals) in the process of tourism development. The results show that the development
\end{abstract}

Received: 15 July 2015

Revised: 5 October 2015

Accepted: 13 October 2015 of ethnic tourism has led to changes in the increase of building land, and the diversification of land use functions with a trend of shifting from meeting local villagers' living needs to satisfying tourists, income composition and uneven distribution of tourism income spatially. Ethnic tourism also led to the deterioration of traditional social management structure, collapse of neighboring relationship, the over- commercialization and staged authenticity of ethnic culture, as well as the gradual vanish of agricultural knowledge with a trend of increasing modern business knowledge and higher education. In addition, these changes, involving livelihood assets from natural, economic, human, social and cultural aspects are interrelated and interactive, which form new evolution characters of ethnic community. This study reveals the conflicts over livelihood approaches which have formed new vulnerabilities to impact on sustainable evolution of ethnic communities. This research provides implications for achieving the 
sustainable development of ethnic communities with the driving force of tourism livelihood.

Keywords: Community evolution; Tourism livelihood; Livelihood assets; Ethnic tourism; Guizhou

\section{Introduction}

Ethnic tourism was firstly proposed by Theron Nuñez (1963), describing any excursion, which tourists experience first-hand the practices of exotic and ethnic culture, and may involve performances, presentations and attractions portraying or presented by small, often isolated indigenous communities and villages, attempts to give the tourist an understanding of the lifestyles of local people, generally ethnic minority groups (Smith 1977; Cohen 2004; Bruner 2005; Yang et al. 2008). Ethnic tourism has long been considered an option for creating livelihoods in poor places (Hall 2006), thereby decreasing the vulnerability of such places. For example, tourism has resulted in both financial and non-financial improvements (Simpson 2009), such as notable income growth (Matthew and Harold 2000), increased job opportunities (Stanisaw 1991), enhanced national consciousness (Susan 1995) and improved women's status (Garcia et al. 1995). Unlike the traditional tourism destinations in rural areas, ethnic communities serve as both a living community and a tourism destination (Oakes 1992; Chow 2005). This dual function of the ethnic community complicates the relationship of all stakeholders, thus resulting in the intricate roles of local residents during the transition period from a farming-dominant economy to a service-dominant economy.

However, as large numbers of tourism projects combined with large numbers of Han Chinese flooding into ethnic areas, harmful effects are exerted on livelihood assets and outcomes because these projects require a range of infrastructure as well as the provision of services from a variety of other industry sectors (Simpson 2009) and the cooperation of multiple stakeholders (Yang 2011). Negative impacts such as conflicts among stakeholders (Wood 1985; Yang 2006; Ying and Zhou 2007; Yang et al 2011), the destruction of the social and cultural fabric of the society (Cohen 1988; Oakes 1997; Lin 2007; Liu 2011), and the transformation of the spatial structure (Wang 2011) and the landscape of the area (Xi 2011, 2015) are of great concern.

Throughout the $21^{\text {st }}$ century, the sustainable livelihoods framework (SLF)-one where the objects are marginal residents in rural areas living in vulnerable environments (Mahony and Zyl 2002) and where the purpose is to achieve a sustainable livelihoods outcome-was proposed by the DFID (Department For International Development in British Government) in 1999 and adopted worldwide (Leon 2007; Mbaiwa and Sakuze 2009; Liu 2011). The SLF mainly consists of a vulnerability context, structures and processes, a livelihood assets pentagon and livelihood outcomes. Ellis (2000) divided livelihood assets into natural (environmental resource based), physical (humanproduced goods, equipment and infrastructure), economic/financial (stocks and inflow of cash), human (population and labor characters) and social capital (social relationships, formal and informal organizations, norms, decision-making mechanisms and leadership). The asset pentagon, which is the foundation of the livelihoods framework, was developed to schematically show the variation in people's access to assets (DFID 2002; Morse and Mcnamara 2013).

Ashley (2000) first adopted the sustainable livelihoods framework (SLF) to analyze the positive and negative tourism impacts on social, natural and human capital of rural residents in Nambia. Shen (2008) added "institutional capital" to the sustainable livelihoods framework (SLF) replacing physical capital and proposed sustainable livelihoods framework for tourism. Since then, the combination of livelihood and tourism research has been applied to the tourism field. Attentions have been paid on the effect of tourism on livelihood assets from economic, social, financial, natural and human perspectives (Tao 2009; Mbaiwa and Sakuze 2009; Mbaiwa 2013; Anup and Resham 2014).

These recent studies on tourism impact and livelihood have deepened and expanded to a comprehensive perspective. However, unlike the traditional tourism destination, ethnic community endowed with exotic culture and unique social structure, whose livelihood assets in cultural and 
social aspects should be emphasized. Furthermore, the studies apply primarily qualitative methods, such as questionnaires and interviews, while little attention is given to quantitative approaches, especially with respect to national capital change. In recent years, spatial analysis methods have been adopted in this field to study tourism's impact on the landscape and land use (Ogutu 2002; Wang et al. 2011; Xi et al. 2011, 2014). By adding a quantitative method to research in the field of tourism impact, landscape transformation and spatial change in natural capital could be identified visually, which complements the shortage of overly descriptive characteristics in qualitative research.

Thus, based on the literature related to livelihood and tourism, a conceptual framework for sustainable tourism livelihoods with increased attention on national and cultural capital is developed and subsequently applied to Qiandongnan, Guizhou Province. Applying qualitative and quantitative methods together, this paper examines and compares the evolution of ethnic tourism communities by identifying changes in livelihood assets that are in different stages of tourism development and explores the tourism impact on livelihood assets from the perspective of local residents aiming to identify the new vulnerabilities limiting sustainable livelihood outcomes and sustainable ethnic community development.

\section{Conceptual Framework}

A conceptual framework was developed based on the sustainable livelihoods framework established by DFID (Scoones 1998; Ashley 2000; Tao and Wall 2009) and the sustainable livelihoods framework for tourism (Shen 2008) to analyze and assess the effects of tourism on traditional livelihoods of the Miao and Dong people in the selected tourism area of Guizhou Province, southwest China - Qiandongnan. Applying the conceptual framework, the socio-cultural issues of ethnic tourism and the complicated relationships among all stakeholders from the perspective of local residents are examined. A new livelihood approach represented by the tourism industry is developing and flourishing based on the livelihood assets created from traditional livelihoods. With more actors involved in tourism, the increasingly complicated relationship and huge investments in tourism have changed livelihood assets and created vulnerabilities in livelihood approaches that challenge sustainable livelihoods outcomes. The framework consists of four parts: vulnerability context, livelihood assets, key stakeholders, and livelihood outcomes (Figure 1). However, this study emphasizes the change of traditional livelihood assets, considering the word limit, with less discussion about other parts.

(1) Vulnerability context: Vulnerability consists of trends (economy, policy, governance, and technology), shocks (crop substitution, external culture shock) and seasonality (price, surplus labor). In this study, the trends in Qiandongnan provide a suitable

Figure 1 Sustainable Livelihoods Framework for Tourism. 
atmosphere for new livelihood approach growth. The economic background is in the transition process from being an agricultural economy to a market economy. The policy from the local government regarding tourism project construction promotes rapid tourism development, technological improvement in communication and agriculture changes the ways of interacting, while the external culture, new crop introduction, and tourism development shock the previous social structure and culture. Meanwhile, as tourism and farming retain the typical characteristics of seasonality, the conflicts between the new and the traditional livelihoods are inevitable and obvious in terms of surplus labor use and pricing. As Figure 1 shows, vulnerability refers to the context of the development process of livelihoods and to the outcome of the whole process. Accordingly, each part of the flow chart represents a mutual effect and is thus closely related to the other parts.

(2) Livelihood assets: In this study, the effects of tourism on traditional livelihoods during the transition process from an agriculture-oriented industry (traditional livelihood approach) to a service-oriented industry (tourism-related livelihood approach) include changes in the living environment (natural capital), education and knowledge (human capital), social management structure and neighboring relationships (social capital), ethnic dances/songs and rituals (cultural capital) and family income (financial capital). As Figure 1 shows, the ideal situation for the sustainable livelihood assets is a pentagon with a balanced livelihood capital percentage. In reality, however, it presents different shapes with different types of livelihood capital, thereby providing a visual perspective of the unbalanced development of a certain capital.

(3) Key stakeholders: Five key groups of stakeholders are involved in tourism and are identified in this study. These include governments at all levels (village level, town level, county level and provincial level), local residents, external businesspeople, tourism companies and domestic tourists. In this study, the only company in the field site is the Xijiang Tourism Company, which is affiliated with the Xijiang scenic administration and is controlled directly by the town government. Many of the stakeholders are not members of a minority group or members of the same minority groups that represent the various interest groups.

(4) Livelihood outcomes: Livelihood outcomes involve the harmonious coexistence of all of the livelihood approaches, including the diversification of sustainable livelihoods and the development of the economy, society, culture and environment.

\section{Research Methodology}

\subsection{Study area}

The Qiandongnan Miao and Dong autonomous prefecture lies in the southeast part of Guizhou province in southwest China and has a population of 3.47 million people and 33 minority groups (Cui 2009). The Miao and Dong people (2.44 million) constitute the majority of the total population. Covering an area of $30,300 \mathrm{~km}^{2}$, Qiandongnan consists of one city, one economic development zone and 15 counties. The forestgrassland-terrace landscape, subtropical climate, well-preserved Miao diaojiao buildings and the Dong drum tower, colorful ethnic festivals, multiple minority cultures and long history offer unique tourist resources.

In the late 1980s, the open reform policy promoted tourism development. As a result, specific communities in Qiandongnan were selected as representative ethnic communities and were accordingly targeted for tourism development. Thus, tourism became an important industry in the late $2 \mathrm{O}^{\text {th }}$ century. In the $21^{\text {st }}$ century, ethnic tourism has flourished and has become a primary livelihood for local residents. By the end of 2005, over 100 tourism communities had been selected, including communities at the national, provincial and prefectural levels, and graded by the state, province and prefecture, respectively, in terms of popularity, nature base, ethnic culture, transportation and infrastructure development (Figure 2). Unlike the minorities in other provinces, such as Yunnan, Guangxi and Tibet, where economic interactions with Southeast Asian countries are more frequent and where there are more industries (Ma 2000), the Miao and Dong people in Qiandongnan effectively have a single livelihood-that is, agriculture-related activities, especially sticky rice, maize, and tuber crops, with fishing and hunting as secondary features. Logging (for house 


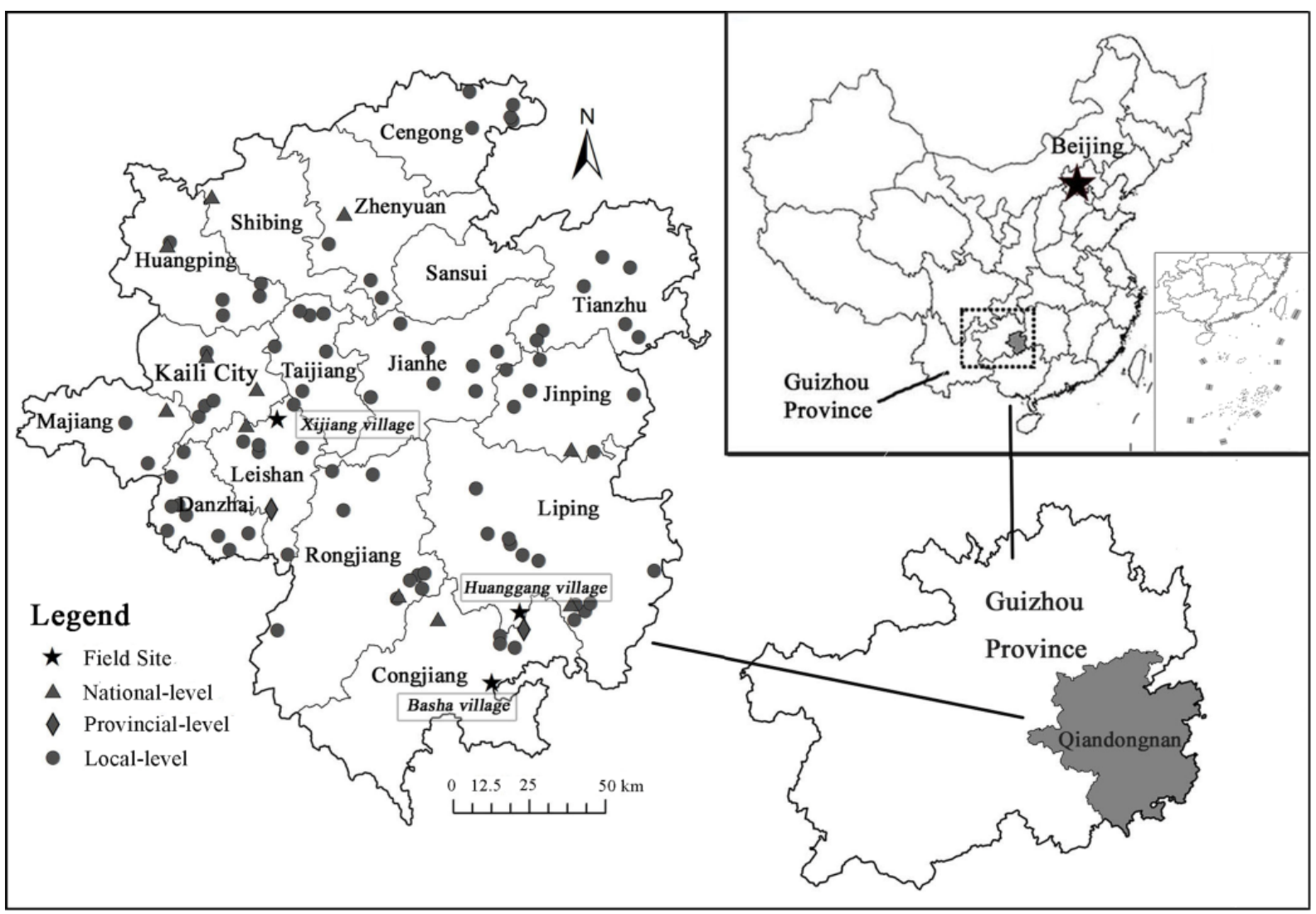

Figure 2 Location of research area and field sites.

construction or trade), fashioning silver products, and embroidery are also traditional livelihood skills (Xiong \& Yang 2010). Agricultural production was and continues to be mainly for subsistence (Xiao 2010). In order to develop tourism, Miao and Dong people have turned out to be tourist guide, some open restaurant, hotel, shop and café, attend in performance, take photos with tourists as a model. Cash incomes from the sale of handicrafts, small livestock, and silver production are now increasing. The vast changes in lifestyles and the increased tensions between the traditional and new livelihoods-tourism livelihood, make Qiandongnan a suitable site for a study on the effects of tourism. The fieldwork was conducted primarily in one community with national level where tourism is in full force (Xijiang $\mathrm{Hmu}$ community), one with provincial level of tourism
(Basha Hmu community), and one without tourism to date but planned tourism development in the near future (Huanggang Dong village). These three communities represent different stages of tourism development in Guizhou Province.

Xijiang $\mathrm{Hmu}^{1}$ community in Leishan county is Located in the mid-western part of Qiandongnan. It has six natural villages ${ }^{2}$ with 1432 households. The Hmu people account for $99.5 \%$ of the population. In 2007 , the entire community was listed as a national-level historic cultural town, and in 2011, it was selected as an AAAA-level tourist destination. As a well-developed tourism community, tourist flows reached 8.51 million and tourism income soared to RMB 4300 million (approximately 691 million USD) by the end of 2014 (Tourism Bureau of Xijiang 2015).

Basha Hmu community in Congjiang county is

${ }^{1} \mathrm{Hmu}$, also known as Qiandong Miao, Mhu Miao, or Central Miao, is one of four sub-languages of the Miao language group in China. Most Miao in Qiandongnan Miao and Dong Autonomous Prefecture belong to the Hmu linguistic group (Lemoine 2008).

${ }^{2}$ Natural village, is also used in contrast administrative villages, which refer to the structural integration of neighboring villages formed by one or several clans or other reasons from natural and spatial perspectives. The administrative village is the basic management unit established by law in China and managed by village committee and party committee, which could cover one or several natural villages (Ho 2001). 
situated in southeastern Qiandongnan. It has five natural villages with 472 households, all of which are Hmu people. In 2005, the community of Basha $\mathrm{Hmu}$ was selected as a provincial-level tourist community. In 2014, the total number of tourists (primarily one-day visitors) reached 123,000 and tourism income had increased to RMB 80.58 million (approximately 12 million USD) (Tourism Bureau of Basha 2015).

Huanggang Dong community in Liping County is Located in southeastern Qiandongnan, this community has two natural villages and 359 households. In 2005, it was selected as a local-level tourism community. Only experts, photographers and backpackers visit the community, and tourism activity did not begin until 2014.

\subsection{Data collection and analysis}

A variety of qualitative and quantitative methods are involved in data collection. Based on the land use raster data of 1980 and 2010 from the Chinese Academy of Sciences, this study applied ArcGIS 10.2 (ESRI company, Redlands, California, USA, 2010) to extract and transfer raster data into rector data of four types of landscape patches, including arable land, forest land, grass land and building land. By adopting formulas from the field of landscape ecology, the patch area (CA), patch number (NP) and landscape fragmentation index (NP) based on ArcGIS 10.2 were calculated. The value calculated has a certain deviation because of the deficiency in the raster data compared to the rector data.

This study also adopted interviews and questionnaires during three months of fieldwork in Qiandongnan in 2013 and 2014 and conducted follow-up interviews with interviewees via telephone or online chatting tools in the four months following our fieldwork (the data collection ended in December 2014). Semi-structured interviews were conducted with twenty government officials from the tourism departments of all levels (village, county, prefecture and provincial). The interviews inquired about policy orientation, tourism decision-making and planning processes and tourism benefits distribution. An additional twenty-five in-depth interviews with traditional elites (Zhailao), local tourist guides, local students, farmers and tourism practitioners were carried out, focusing on social management systems, livelihood approaches, tourism impact perception and social relationships.

Questionnaires were administered to understand the expectations and the experience perceptions of tourists and to obtain the perception that local residents had regarding the impact of tourism. Approximately 150 online questionnaires and 280 on-site questionnaires regarding the tourists' expectations and experiences were distributed, and 347 were completed, for a response rate of $81 \%$. Respondents were also encouraged to comment on the authenticity of the tourism community. Furthermore, of the 280 questionnaires administered to residents in the six communities, 265 were returned, for a response rate of $94.6 \%$. The respondents, which included traditional elites (Zhailao), local tourist guides, farmers and tourism practitioners, were asked about their attitudes towards tourism and their reactions to the new livelihood approach and its effects on the social inner-management structure, neighboring relationships, and traditional production modes. By analyzing tourism plans, the study is able to utilize the tourism land use data to compare the changes before and after tourism development. Furthermore, the official documents provide us with insight into the policy orientation about preferring the tourism industry to the agriculture industry.

Thus, this study explores and discusses the changes in livelihood assets from five perspectives regarding the effects of tourism on the traditional livelihoods of the Miao and Dong people by coding all of the qualitative data and analyzing the land use data.

\section{Results}

\subsection{Natural capital}

The Miao and Dong communities are situated in the typical forest-grassland-farmland ecosystem. Housing, mountains, streams, farmlands and woods are distributed in a circular configuration around the drum tower for Dong community and the well for Miao community (Luo 2008). Under the context of typical mountainous areas in Qiandongnan prefecture, Miao and Dong 


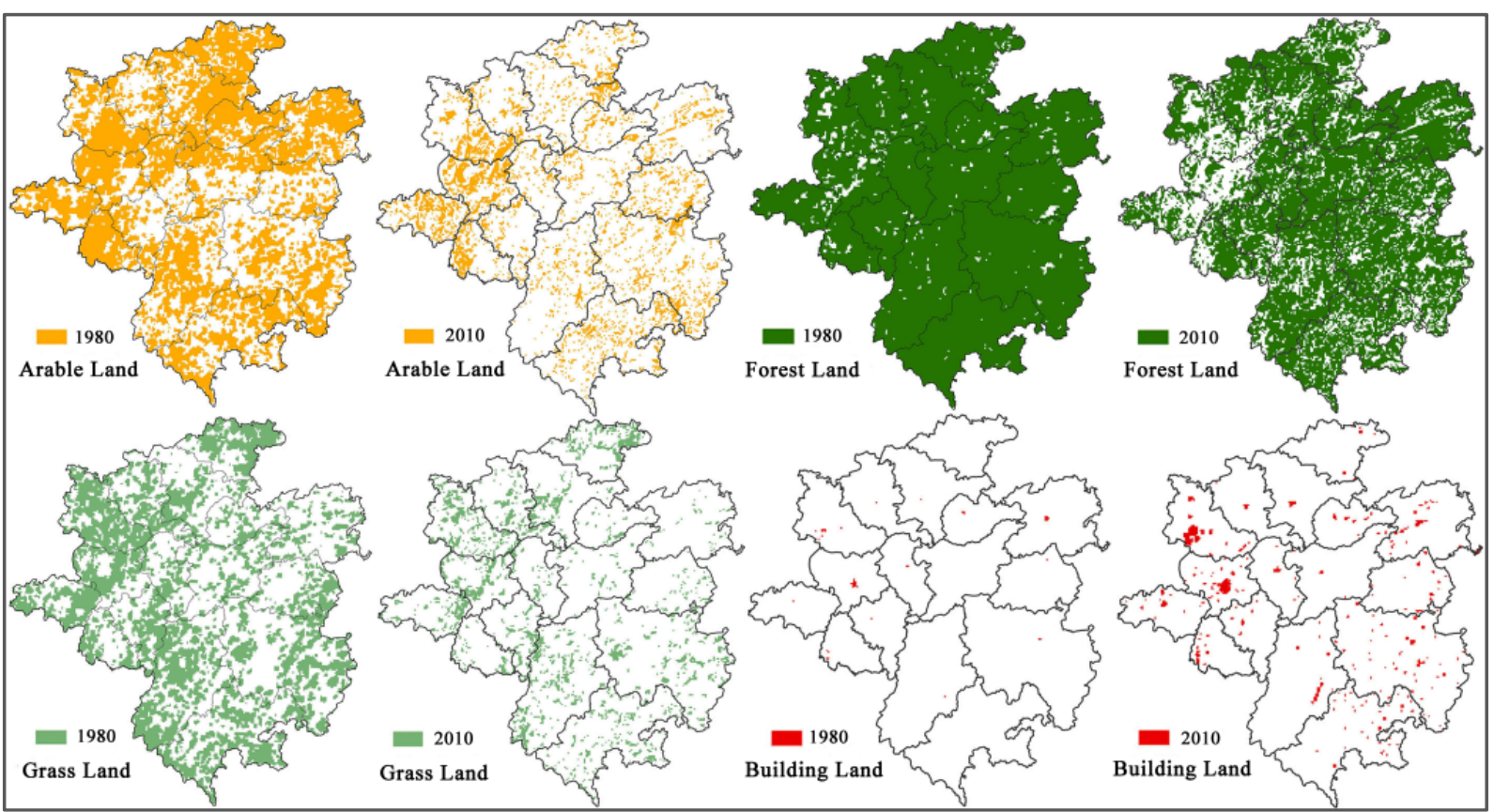

Figure 3 Land use change from 1980 to 2010.

communities are mainly located in valleys and are restricted within a zonal area (Cui 2009). Thus, the arable and forest lands are precious and limited for local residents making a living by farming, hunting and fishing. The main tourism landscape consists of farmland and forest, which has experienced a dramatic change within the context of urbanization and tourism development since the open reform policy was proposed in 1978. The continuing tourism demand in the market and increasing tourist arrivals annually result in a heavy demand on the tourism service facilities, infrastructure construction as well as the building of new tourism attractions. It is evident that arable, grass and forest lands decreased substantially as building land area increased. From Figure 3 and Table 1, arable, forest and grass lands constitute the main landscape, though they have declined at a staggering rate as building land has increased during this thirty-year period. The landscape fragmentation index of arable, forest and grass lands experienced a dramatic shift towards centralization, while building land appears to be decentralized, with an increased number of scattered patches and areas. Accordingly, it is evident that increasing human intervention has had an effect on natural capital and has altered the landscape.

Similarly, this study found that the community
Table 1 Land use change in 1980 and 2010

\begin{tabular}{|l|l|l|l|l|}
\hline Land use type & Year & $\mathrm{CA} / \mathrm{km}^{2}$ & $\mathrm{NP}$ & $\mathrm{FN}$ \\
\hline Arable land & 1980 & 26929.14 & 36730 & 121.07 \\
\hline \multirow{2}{*}{ Forest land } & 2010 & 4697.89 & 2060 & 6.79 \\
\hline \multirow{3}{*}{ Grass land } & 2010 & 29061.06 & 49203 & 162.19 \\
\hline \multirow{2}{*}{ Building land } & 1980 & 13261.97 & 14789 & 48.78 \\
\hline & 2010 & 3425.06 & 994 & 3.28 \\
\hline & 2010 & 709.78 & 23 & 0.076 \\
\hline
\end{tabular}

Notes: CA: patch area; NP: patch number, the greater the number is, the higher fragmentation degree; FN: $\mathrm{FN}=\mathrm{N}_{\mathrm{i}} / \mathrm{A} \times 100, \quad \mathrm{FN}$ is index of landscape fragmentation of a certain type. $N_{i}$ is patch number of $i$ patch, A is whole area of all types of landscapes. The higher the $\mathrm{FN}$ is, the higher fragmentation degree. The value calculated in this table has a certain deviation because of the deficiency in raster data compared to rector data.

of Xijiang $\mathrm{Hmu}$ is facing, albeit microscopically, landscape changes along with the rapid development of tourism. To develop and manage tourism activities that meet the needs of the tourists, local governments (mainly at the town and county levels) proposed to plan the community around land use, sanitation and transportation infrastructures. According to the "Constructional detailed planning of the community of Xijiang Hmu", the plan transferred nearly 12 hectares of 
arable/grass/forest lands to commercial, service, hotel, entertainment, road, parking and new residence lands, with a planning area of 85.82 hectares (Figures 4, 5 and Table 2). The riverbank area has become the center of tourism activities and has attracted a large number of external businesspeople who rent houses from local residents. Relocating local residents and new external residents to the west and northeast areas and building new residences required the sacrifice of 3.43 hectares of arable/grass/forest lands. Before the development of the tourist area, an elementary and a middle school were located on both sides of the river, land that has subsequently become commercial land. The schools, as a result, were relocated, until the end of 2013, to the top of the mountain outside of the community and the county, respectively, (interview with government official in Xijiang Hmu Community, 28 April 2013). New roads were planned and built within residential areas in high altitude areas, thereby providing tourists with greater access to these locations. By the end of 2014, there were 143 guesthouses and hotels, 86 ethnic shops, 74 restaurants, 15 tea bars, numerous photo studios and 272 shops selling silver products and either selling or renting traditional costumes (Tourism Bureau of Xijiang 2014). These tourism facilities are mainly located near the Baishui River and span an area of 7.5 hectares. In addition, over $50 \%$ of rural residences were transformed into multifunctional buildings that combine guesthouses, show rooms, shops and cafeterias (interview with government official in Xijiang Hmu Community, 6
November 2014). Today, the commercial area has become the core zone for tourist entertainment, especially at night, with every house lighting its lamps, for a total of more than 4000 lamps, from 7 p.m. to 12 a.m. for the purpose of tourist activities. According to the survey administered as part of this study, $86 \%$ and $69.2 \%$ of the local residents complained about the levels of noise and pollution, respectively, in today's community. Furthermore, there have been many disputes about the decline in the quality of living due to interference by the numerous tourists flooding into the community and the rapid development of tourism in the area.

The findings indicate that ethnic tourism has greatly changed land use modes and the landscape of the traditional community from both prefectural and community perspective since tourism started. Land use function was also complicated by changing from meeting villagers' living needs to satisfying tourists' demands, which directly weakens the traditional agricultural function, especially for communities with a high level of tourism. Xijiang Hmu community, for example, has converted from a traditional rural village to a modern town with the growth of building land use and the development of artificial landscapes, which threatens the loss of the community's rural character.

\subsection{Financial capital}

Prior to the 1980 s, Miao and Hmu residents in Qiandongnan depended on agriculture and other farming-related livelihood approaches, and

Table 2 Planning land use in Xijiang Hmu community

\begin{tabular}{|l|l|l|l|l}
\hline Land use type & Previous area (ha) & Increment & Planning area (ha) & Planning percentage (\%) \\
\hline Commercial land & O & +1.5825 & 1.5825 & 1.82 \\
\hline Service land & 0.8982 & +1.1079 & 2.0061 & 2.31 \\
Hotel land & 0.0858 & +2.0116 & 2.0974 & 2.41 \\
\hline Entertainment land & 0.1305 & +1.6993 & 1.8298 & 2.10 \\
\hline Exhibition land & 0 & +0.1261 & 0.1261 & 0.14 \\
\hline Square land & 0 & +0.3947 & 0.3947 & 0.45 \\
\hline Road land & 1.9132 & +1.4933 & 3.4065 & 3.92 \\
\hline Parking land & 0 & +0.4638 & 0.4638 & 0.54 \\
\hline Old residence land & 19.44 & 0 & 19.44 & 22 \\
\hline New residence land & 0 & +3.43 & 3.43 & 3.94 \\
\hline Medical and health land & 0.2125 & -0.0461 & 0.1664 & 0.19 \\
\hline Water land & 4.0180 & 0 & 4.0180 & 4.62 \\
\hline Green land & 1.0695 & -0.5882 & 0.4813 & 0.55 \\
\hline Arable land & 40.3125 & -8.142 & 32.1705 & 36.97 \\
\hline Forest land & 18.4227 & -2.73 & 15.6927 & 18.04 \\
Total & 87.0073 & 0 & 87.0073 & 100
\end{tabular}

Source: Tourism Bureau of Qiandongnan (2007) Constructional detailed planning in Xijiang Hmu community. 


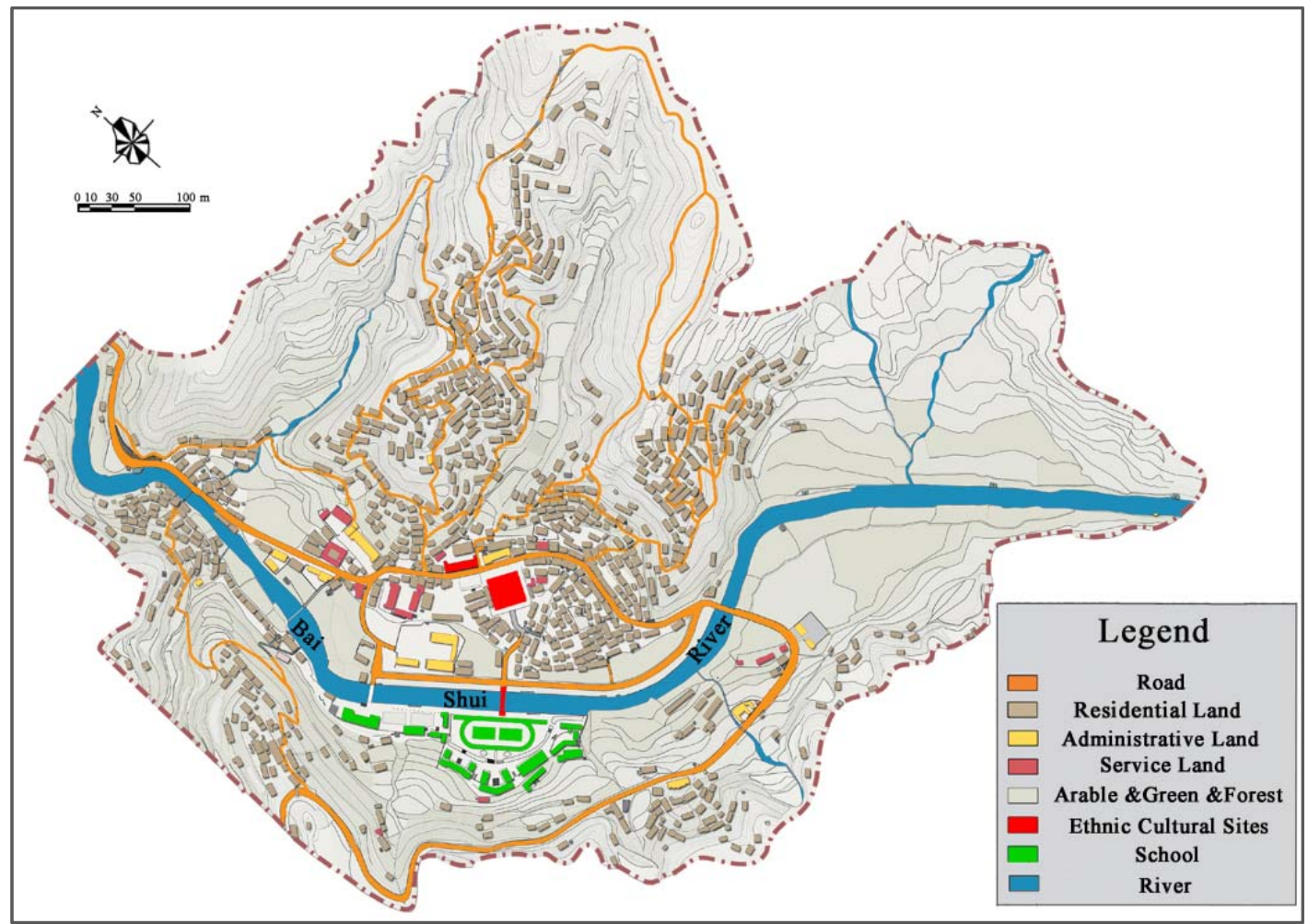

Figure 4 Landscape changes-before tourism development.

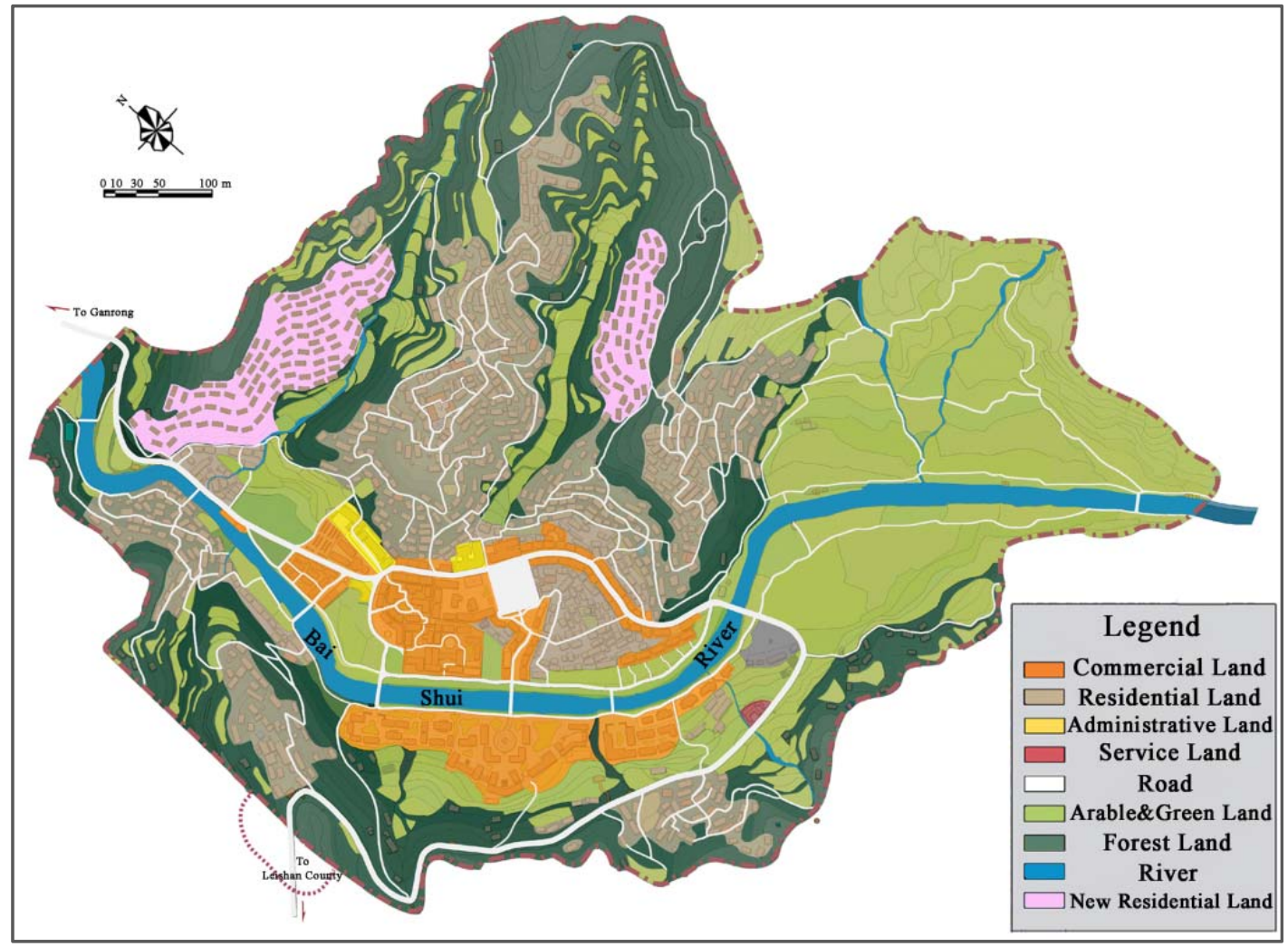

Figure 5 Landscape changes-after tourism development.

farming-related income was the main income source for local residents (interview with Professor
Cui Haiyang, ethno-ecologist at Guizhou University, May 2013). Since the open reform policy in 1978, 
rural-urban mobility has become the primary choice for making a living and diversifying livelihoods for rural residents. According to the latest statistics from the Qiandongnan employment agency (2014), more than 800,000 farmers worked outside of Qiandongnan by the end of 2013. They preferred coastal cities, where there were more job opportunities and better salaries in laborintensive factories. This research summarizes the seven main income resources in today's Qiandongnan - wages, farming, forestry, animal husbandry, fisheries, secondary industries and tertiary industries (Figure 6, Qiandongnan Statistics Bureau 20002014). Wage income

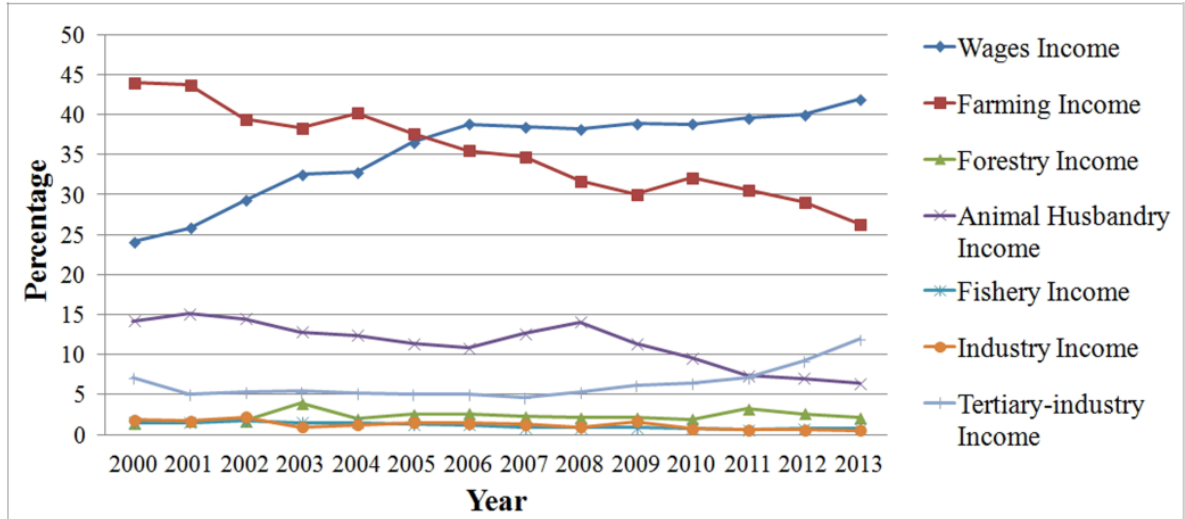

Figure 6 Per capita total income of rural residents (percentage).

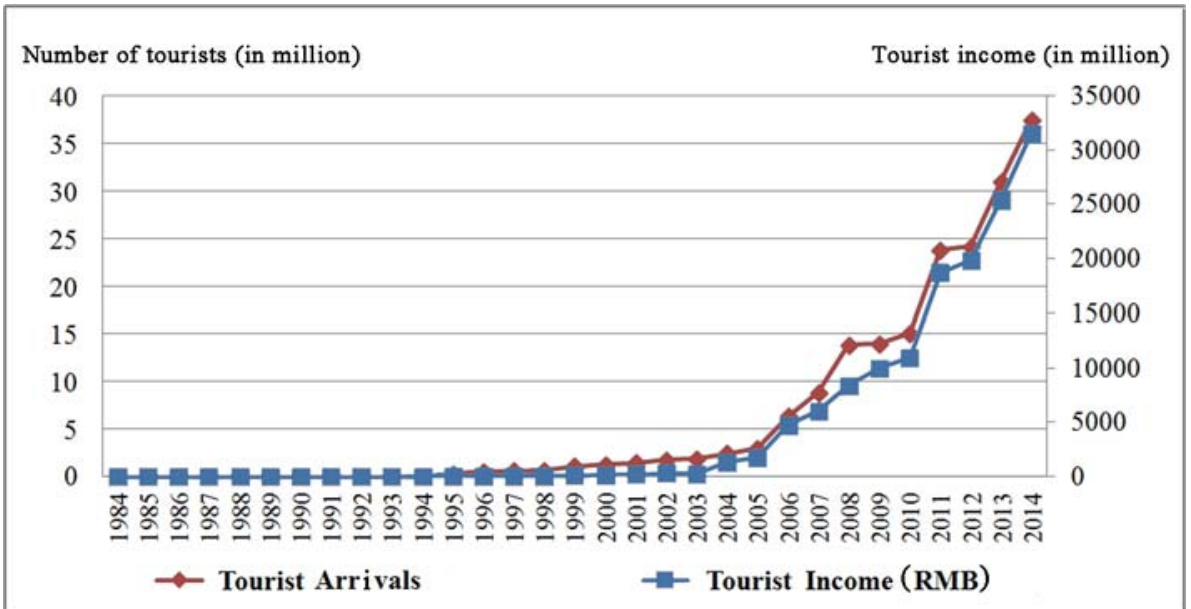

Figure 7 Tourist flow and income from 1984 to 2014. development promotes business activities including restaurants, ethnic shops, hotels and other entertainment venues, the exclusive ethnic items, such as handicrafts, silver products, local foods and ethnic accessories, created and provided by local residents are popular tourism products. Similarly, performances that display the local ethnic dances and songs have become popular entertainment venues for which the local residents charge money. Local residents are actively participating in tourism activities as tourist guides, restaurant and/or hotel owners, tourist performers, souvenir dealers, photographers, and even photo models posing in traditional attire for tourists. In some cases, local residents have opened modern shops and cafeterias to satisfy the wide variety of needs of the tourists. Meanwhile, tourism development also absorbs many residents who once were migrant workers by providing them with job opportunities, thus pushing them to live in the countryside. Tourism-related livelihood 
approaches enrich job types and diversify income resources.

According to the results from questionnaires administered to residents in ethnic communities with tourism activities, $89.3 \%$ of the residents participate in tourism activities on some level. Furthermore, $63.2 \%$ residents who have income from various tourism-related activities comprised more than half of the total income in the community. For example, the per capita income of the community of Xijiang $\mathrm{Hmu}$ increased to 8250 RMB in 2013 from 2050 RMB in 2008. Furthermore, while wage and farming incomes accounted for the majority of the income prior to 2008, income from tourism activities in 2013 exceeded $70 \%$ of the total income for the community (interview with officials of Xijiang's town government, 7 November 2014). Before tourism development, the per capita income of residents in Basha $\mathrm{Hmu}$ community hovered around $2000 \mathrm{RMB}$, while it rocketed to $4600 \mathrm{RMB}$ in 2013 (interview with community chairman, 20 April 2013). This community had a similar experience, with over $50 \%$ of its income coming from the tourism industry. Huanggang Dong Community is still dependent on agriculture and the employment of its residents in neighboring large cities, though it is slated to develop its tourism industry. This is evidenced by the fact that, in March 2013, the county government provided funds to build a new road as part of the initial efforts to develop its tourism sector (interview with community chairman, 21 April 2013). Tourism development has changed the income source structure by increasing the income from service industries and decreasing the wages and income from the farming and agricultural industries.

The vast economic improvement driven by tourism activities in a short time is evident, while the tourism income gap within and among communities is getting wider because of the limited and unbalanced opportunities for tourism participation, which will result in deteriorating neighboring relationships (see 3.3 social capital).

\subsection{Social capital}

The traditional social management structure, neighboring relationships and power structure have also undergone changes during the transition from an agricultural industry to a service industry. Considering the management of different resources and the diverse impacts on communities, Gong (2011) identifies three types of elites in ethnic communities: the traditional elite, the political elite, and the economic elite. The traditional elites have local prestige and clan forces, such as Zhaolao. Since the founding of the "new countryside", the previous Yilang organization and Kuanyue organization in the Miao and Dong communities transformed into the Zhaolao organization, which serves as the assistant to political elites. The political elite refers to those cadres of individuals who have the political rights of the communist party and government organizations, such as the community chairman, community secretary and other community personnel. The final group, the economic elites are those commercially minded villagers who are considered to be more financially successfully than the average local resident. Economic elites in the Miao and Dong ethnic community of Qiandongnan are often those tourism practitioners who are living in a convenient location for tourism development or have special powers and therefore benefit greatly from tourism by participating in tourism activities.

As the important cultural stewards and components of local non-government organizations, traditional elites organize and manage local residents' lives and agricultural activities (Xia 1990; Zhou et al. 2007). Traditional elites are generally elected by local residents, possess extensive knowledge about the community's history, its festivals and its rituals, and have the personal charisma to address disputes within and among communities ( $\mathrm{Wu}$ 2013). Traditional elites can only be found in minority communities, as an exclusive existence and representation the democratic social management at the grass-roots level nationwide, and their aboriginality and uniqueness constitute an important part of tourism attractions in communities. "Visiting traditional elites" has become a choice and purpose of ethnic tourists to approach the "local king of the community" (Interview with tourists in Xijiang Hmu community and Basha Hmu community, May, 2013). Furthermore, there are several hereditary elites who have inherited the position from the older generation. The community of Xijiang Hmu provides such an example (interview with officials 
from the town government of Xijiang, 27 April 2013). Thus, traditional elites have more opportunities to participate in and benefit from tourism activities, such as opening guesthouses and restaurants, than other residents because of their special status in the eyes of the outsider (interview with local residents from the communities of Xijiang and Basha, April 2013). According to the 2007 "Constructional detailed planning in Xijiang Hmu community", members of the Zhailao system in Xijiang, especially the hereditary elites, receive special treatment with respect to developing tourism (Guzangtou ${ }^{3}$ and Huolutou4). The local government invested in building a museum in the home of Guzangtou, expanding his home, which was then used to exhibit the drum and other objects of the festival. With the deepening and furthering of tourism participation, traditional elites have transitioned towards economic elites, and the function of traditional elites has also shifted from a social function to a tourism function. Local residents, however, noted that because the Zhailao elites are blessed by their ancestors: it is their duty to serve the local people, and accordingly, it is inappropriate for them to use their status to make large amounts of money so overtly. Thus, these elites face the threat of losing community respect from the local residents, which in turn challenges the inheritance and continuation of the traditional social management system.

The political elites, who are the decisionmakers, possess more rights and resources than local residents to participate tourism planning, especially because of China's government-oriented management. The intervention by various levels of political elites with respect to establishing regulations and engaging in tourism planning as well as guiding the behaviors of local residents is obvious. For instance, conflicts arise from ticket charging, tourism benefit distribution, tourism planning, cultural heritage appraisal activities, etc., all of which have caused overt and covert resistance from local residents as they compete for more rights in the process of tourism development. Among the three communities, each of which is at a different stage of tourism development, the tensions between the local residents of Xijiang $\mathrm{Hmu}$ Community and the governments of all levels are becoming increasingly intense. When tourism development was first introduced in 2008, ticket charging was an annoying inconvenience for local residents because they were constantly required to show certificates to prove their identity when they visited the community. All schools were also required to move from the community for commercial purposes and relocate to other villages or towns by the end of 2013 (follow-up interview with local students, 7 November 2014; see Figure 4). This not only increased education costs but also created problems for many of the students because the schools were so far from their homes. Meanwhile, to accommodate more households and external population growth, 3.43 hectares of arable and forest lands in higher altitudes were transformed into new residential areas (see Figure 5), causing many farmers to lose farmland and thus their livelihoods (interviews with farmers who had lost land, 5 November 2014). As a result, they were forced to change livelihoods. As one farmer said, "Like my house, which lies in a higher altitude area, fewer tourists come here. They prefer to live near the river (Baishui River). We still depend on agriculture, while the young people work in large cities. Now, we have lost our land. We have to buy all of our groceries, but the job of selling tourism souvenirs, which was given by the government as compensation for losing my land, cannot support a family. I also cannot compete with other external businesspeople."

In early 2013, the local government forbade local residents to drive their cars into the community as a way of maintaining the traditional community image. This regulation caused overt resistance from local residents as they protested against the government's decision. In February, local residents prevented tourists from entering the community by parking their cars on the roadway as a last resort to compete for their right to park in the community rather than in the parking area that was built for tourists. As one anonymous resident said, "the authorities regard our community as a

\footnotetext{
3 Guzangtou of Xijiang is responsible for organizing bullfights and ancestor worship. According to historical tradition, only the youngest son of the previous Guzangtou could become the new Guzangtou in the village of Xijiang Hmu.

${ }^{4}$ Huolutou in Xijiang is responsible for organizing agricultural activities. According to historical tradition, only the oldest son of the previous Huolutou could become the new Huolutou of the village of Xijiang Hmu.
} 
tourism attraction to develop tourism, but we are living here, it is our home" (interview with local residents of Xijiang, 28 April 2013). The political elites struggle with local residents for tourism benefits through overt intervention. In addition to the regular wages, they also took more opportunities to profit from tourism with their significant power and wealth of resources, for example, by directly investing in businesses or indirectly operating businesses in the name of their relatives within the community (Interview with local residents and government officials of Xijiang, 27 April 2013). The basic function of political elites has weakened as they have sought to maximize economic benefit from their position of serving people.

The unbalanced development of tourism opportunities is altering the relationship between economic elites and other residents of the community. Economic elites, for the most part, belong to the core tourism area and thus benefit from their convenient location, while the residents in the buffer and peripheral areas do not have equal opportunities to benefit from tourism. According to an investigation of the community of Xijiang Hmu community conducted by the Guzhou Normal University in 2012, $97.2 \%$ of the residents in the core tourism area participated in tourism activities, but only $23 \%$ and $11.2 \%$ of the residents from buffer and peripheral areas, respectively, participated in tourism activities. Furthermore, 89.8\% of the residents admitted that the gap between the poor and the rich is becoming increasingly larger ( $\mathrm{Li}$ et al. 2013). Similarly, neighboring communites are facing the same problem. Initially, neighboring communities farmed, hunted, celebrated and even shared manpower and material resources when necessary to sustain a harmonious relationship with each other (interview with Professor Cui Haiyang, ethnoecologist of Guizhou University, May 2013). According to the fieldwork in Huanggang Dong Community, many residents became dissatisfied with the tourism development opportunities compared to those of their neighbor - Xiaohuang Community, the birth place of Dong Big Song, had 68,500 tourists and tourism income of 35.9 million Yuan (5.3 million USD) in 2013-and therefore refused to help their neighbor by not sending singers during the peak tourism season to assist the neighbor's development. What was once a harmonious relationship between two neighboring communities deteriorated when, in October 2013, Huanggang Dong Community received funding from the government to build a road in preparation for the development of its own tourism industry.

With development of tourism in ethnic communities, the traditional elites and political elites have integrated into economic elites with special status and powers, which they have devoted to realizing maximum economic benefits. The change of the power structure complicates the relationship of all of the stakeholders and causes complaints and resistances from local residents, which results in the deterioration of neighboring relationship and the vanishing of the traditional management structure.

\subsection{Cultural capital}

In ethnic communities, indigenous culture and ethnicity are the essence of tourist attractions. Ethnic culture and traditions are usually transformed into tourism products by using labels, cultural symbols, guides, mannequins, and living re-enactments of traditional activities (Yang et al 2008). Forms of cultural representation include showcasing the various traditions of indigenous people, their values and lifestyles, which are adapted to suit tourists' tastes via perceptible cultural materials, cultural festivals and rituals as well as tourist performances.

The perceptible materials in ethnic culture in Miao and Hmu communities contain architecture, arts, crafts, costumes, rural landscape and means of production and other items tourists can directly see and feel. Agriculture, forestry and fishing in the special grass-forest-farmland ecosystem have become the primary livelihoods of the Miao and Dong communities in Qiandongnan after a long process of mutual adaption and interaction with the surroundings. It is the traditional sticky rice planting cultivates the terrace landscape, the special agricultural tools, the complex rice-duckfish ecosystem, the festivals and the other related cultural aspects in which the tourists are most interested. According to the questionnaire, tourists indicated a fondness for the spectacular paddy terrace (89.3\%), ethnic festivals (86.2\%), ethnic clothes (83.3\%), ethnic performances $(84.1 \%)$ and 
ethnic architecture (85.7\%). However, the cultural materials are changing and vanishing because of the conflicts between two industries-agricultural and tourism-and the decline of traditional agriculture. As indicated in sections 3.1 and 3.2 regarding the natural and financial aspects, the quick profitability of tourism benefits has caused residents to prefer tourism activities to traditional farming activities. The rural landscape is changing due to shifts in the land use function, with a decrease of arable, forest and grass land and an increase of building land. Meanwhile, traditional agricultural activity follows a strict schedule and is a labor-intensive activity. However, tourism activities are also time and labor intensive, and as a result, the local people are unable to adhere to the strict planting schedule because they lack both the time and the labor resources needed for farming during the busy tourism season. Therefore, the majority of the local residents choose to plant hybrid rice with chemical pesticides to speed up productivity. Accordingly, the higher the levels of tourism have resulted in fewer households planting traditional sticky rice. Currently, $90 \%$ of the residents in the community of Xijiang Hmu prefer hybrid rice, while only $10 \%$ of the residents in the community of Huanggang Dong choose hybrid rice. In the community of Basha $\mathrm{Hmu}$, there is an equal percentage of hybrid rice and traditional sticky rice growers (Interview with local residents and government officials of Xijiang, 15 November 2014).

Traditional crop substitution interrupts the inheritance and continuation of the rice-farming culture, which is the basis of the tourism attractions. This is most evident when considering that the traditional agricultural tools and support facilities related to the production of sticky rice have either vanished or been altered. For example, traditional toilets in Huanggang Dong Community were built on a fishpond or farmland as a part of the whole complex rice-fish-duck ecosystem to provide fertilizer. As a result, residents did not need to add pesticides or chemical fertilizers. This type of toilet, however, has vanished from tourism communities and been replaced by modern toilets, as in the communities of Basha and Xijiang Hmu. Although local residents (89.5\%) accept this change, modern toilets are not ecologically sustainable, as they discharge waste directly into the river, thus impacting the residents in downstream areas (Cui 2009). The same is true of the grain drying rack, which is used for drying sticky rice with a long straw. The sight of the grain drying rack with sticky rice during harvest attracts many photographers and tourists (interview with residents and photographers of Xijiang $\mathrm{Hmu}$ Community, April 2013). However, this sight is gradually vanishing in high-level tourism communities because residents prefer hybrid rice with a short straw.

The festivals and rituals are mainly derived from traditional crop planting seasons and follow a strict timetable. The Miao and Dong people worship nature, as they are highly dependent on it; they celebrate special festivals and participate in religious activities where they pray to nature and their ancestors for a good harvest. According to the growth and planting cycles of different crops, activities such as sowing seed, transplanting rice, manuring, harvesting and sun-curing are celebrated in the hopes of receiving the blessings from nature and their ancestors. Thus, the festivals adhere to a typical schedule similar to that of the agricultural activities (interviews with Zhailao, local residents in field sites, April 2013). However, to attract more tourists, some festivals and rituals change the time they are held and the procedures that are followed (interview with local residents from the communities of Xijiang and Basha Hmu, April 2013).

As an anonymous resident from the community of Xijiang Hmu said about the Guzang festival5 of today, "There is a strict rule and timetable to the dance, to welcome the guests and to kill the pig, which has been passed down for many generations. For the Guzang festival of 2010, they (the government and several traditional elites) changed the timetable and changed the procedures just for the tourists."

An anonymous resident from Basha $\mathrm{Hmu}$ Community expressed the same concern: "As the last tribe with guns, our guns were used for hunting and for safeguarding our homes. The welcoming ceremony for tourists designed by the government requires us to shoot towards the sky continuously for two or three minutes. This is not our culture,

5 The Guzang festival is the largest and most important ancestor worship festival of the Hmu people. Celebrated every 12 years, the festival lasts for 3 or 4 years depending on the area where it is held. 
and it is just a show."

Tourism turns culture into commodities, as it is staged, packaged and sold to tourists, resulting in a loss of authenticity (Cohen 1988; Oakes 1997; Urry 2002; Liu and Jiang 2011). For example, the staged performance of ethnic dances and songs is a famous art form, which conveys the ethnic culture to outsiders (Tao and Wall 2009). There are two types of ethnic dances and songs: the first is usually performed on a daily basis as a way for residents to communicate and entertain, and the second type is only performed during important festivals and rituals at specific times. Because the tourism planning projects are mainly operated under the control of government at all levels, the authorities have the great autonomy in selecting and marketing cultural items and tourist performances. Thus, it is common to see that the local government has organized and trained a professional song and dance troupe for performance. There are two daily performances in Xijiang Hmu Community and one performance in Basha $\mathrm{Hmu}$ Community. In Xijiang $\mathrm{Hmu}$ community, all of the actors are professional dancers and students in local universities, most of whom do not belong to the minority group. In an attempt to attract more tourists, performers have to abandon everyday clothes to wear traditional ethnic costumes (working clothes). The staged authenticity is used by tourism performers to recreate the past while protecting the backstage authenticity (MacCannell 1973). After the tourist shows, the actors return to modern life. Meanwhile, the modification and reconstruction are also identified in tourist shows catering to tourists' acceptance and appreciation. According to the government officials (interviews with government officials in Xijiang and Basha Hmu communities, April 2013), tourists can only experience limited aspects of the culture and traditional lifestyle due to their restricted travel time, thus the shows need to be altered to make them more acceptable for tourists.

Thus, the incorporation of modern factors in ethnic songs and dances has been evidenced (Simpson 1993; Donaldson 2007), and the original meanings of the traditional dances and songs have been lost in an effort to meet the needs of tourists, a fact admitted to by the experts (Cui 2009; Luo 2008).

\subsection{Human capital}

Economic benefits from the rapid development of tourism in Xijiang have resulted in increased income levels for the residents of the area. This means that an increasing number of residents can now afford to provide higher education for their children, and they also have the financial means to engage in business activities. In addition, the people of Xijiang have increased opportunities to communicate with the Han Chinese people and thus have been able to improve their ability to speak Mandarin. Of the three communities examined in this study, Xijiang Hmu Community had the greatest percentage of residents who had obtained a higher education and mastered Mandarin (interview with government officials from the Tourism Bureau of Qiandongnan, 14 November 2014).

The tourism industry is comprehensively composed of food, shelter, transportation, travel, purchase and entertainment. A diverse portfolio of tourism activities brings new knowledge related to business and service, which is quite different from the traditional agricultural knowledge associated with rural life. This knowledge diversification changes the outlook of local residents. There were over 260,000 rural residents (41,000 direct tourism practitioners) participating in tourism activities in Qiandongnan by the end of 2013 (interview with officials of the tourism Bureau of Qiandongnan, 13 November 2014). Diverse knowledge is needed and provided for the different roles associated with tourism development, and the government provides training classes related to specific jobs in the tourism industry for local residents. Residents now place greater emphasis on their new livelihoods and exhibit increased economic interest as the agricultural economy continues to decline, thus resulting in a decline in agricultural knowledge.

Farming activities and agricultural knowledge are a part of the tourism attraction in ethnic communities, and they represent tourism commodities in the market. However, more and more residents prefer tourism-related business activities with sound economic benefits, abandoning their previous source of capital in favor of tourism development. As in the community of Huanggang Dong, the local residents are good at 
farming and possess a rich knowledge related to agriculture. However, the typical agricultural knowledge is now restricted to the adults and elders because the young people today choose to work outside of the community or pursue an education rather than learning about farming and agriculture. As a young girl in Huanggang Community said, "I do not know how to farm. I guess I will go to the field when I get married to help my parents-in-law. Our peers work in cities and only come back during the harvest seasons and festivals. I'd say that we are not good at farming compared to the older generation (21 April 2013)."

The community of Xijiang Hmu has achieved a level of high tourism, with 2800 direct tourism practitioners, which amounts to approximately $32 \%$ of the community's population. Local residents have abandoned agriculture, fishing and forestry and devoted themselves to tourism development. Many of them have become successful businesspeople and economic elites in the community and are doing well in the service and business fields. During our fieldwork, a new job was found to have emerged along with the rapid development of the tourism industry, that is, farming for tourism practitioners during the farming season. These workers are generally locals living in high altitude areas without tourists or come from neighboring communities. Actually, people used to help neighbors for free during the harvest season in the community of Xijiang Hmu, but it has become a job with an hourly or daily salary. From the perspective of the residents, the community has shifted from an agricultural society to a business society, placing greater emphasis on individual interests and transactions (interviews with residents of Xijiang, 27 April 2013).

Meanwhile, the online marketing knowledge driven by modern technology and competition with external businesspeople has become a necessary skill to attract and gain access to tourists. To occupy a greater share of the market and to compete with external businesses, local residents felt the need to enhance their technological skills and computer knowledge. At present, there are 118 guesthouses (142 in total) in Xijiang Hmu that have their own booking websites and ads online (investigation of accommodation websites such as Ctrip.con, Qunaer.con and Yododo.cn), and these residents are quite familiar with computers and the new applications related to tourism. However, at the time of data collection, Huanggang Dong Community did not have Internet access, and there was only one computer, which belonged to a teacher in an elementary school. Only the young people who work in cities or study in schools possess knowledge of computers and social networks, and that knowledge is limited. In Basha $\mathrm{Hmu}$, the tourist sources are mainly the government and the day visitors who regard Basha as a stop but prefer to live in other, more wellknown tourism villages or towns. I found only five guesthouses, three stores and one souvenir shop in the community during my fieldwork. Thus, the residents of Basha have less knowledge of modern technology than Xijiang but more than Huanggang.

Furthermore, the increased opportunities to communicate with the Han Chinese people mean the Han Chinese can influence the local residents' traditional views, facilitate the learning of Mandarin and the loss of the ethnic dialect, which can provide greater access to new lifestyles and modern devices for living and working. The local residents of Qiandongnan are on the path toward becoming a modern civilization at the expense of traditional ecological, agricultural and human knowledge.

\section{Discussion}

Since 1980, the main theme of rural livelihood diversification in China has been rural to urban migration, shown as migrant workers (Chan 2011), and urban to rural migration, presented as rural tourism ( $\mathrm{Li}$ et al. 2015, in press). This is especially the case in regions with high percentages of ethnic minorities where poverty levels are a state concern, and while it is suggested that ethnic minorities have more difficulties in assimilating into urban Han society (Bhalla et al. 2006). Hence, ethnic tourism has become the key livelihood strategy alongside agriculture in ethnic communities. Our research has shown that new vulnerabilities created by tourism development, such as the confrontations, conflicts and tensions over livelihood approaches in five livelihood assets that have arisen in these communities, which will result in the different livelihood outcomes and evolutive characters, shown 
in Figure 8. Given the government's wholesale support for rural tourism, it is easy to abandon traditional resource-use systems, turn local natural resources into commodities, impart a negative effect on the local ecosystems and turn communities into emerging centers of resource allocation and even modern towns all in an effort to maximize economic interests through the development of ethnic tourism.

Ideally, local case studies such as this one, which provide detailed understandings of local livelihood strategies, stakeholders' reactions and changes in livelihood assets in different tourist area life cycles, can help confrontations,

vulnerabilities and tensions to be better managed, controlled, and perhaps avoided.

Most importantly, government agencies involved in tourism planning-those with the greatest power and resources in this socialist state-need to cautiously consider and understand overt and covert changes in livelihood assets, as well as locallevel confrontations, along with the concessions and compromises they bring, to achieve longerterm diverse and sustainable livelihoods. It is far more likely that each stakeholder will continue to fight for their rights and complicate their relationships with others, constantly needing to establish suitable coping strategies to advance their own vision of equitable returns from tourism and sustainable livelihoods. Accordingly, it is crucial to analyze the effects of tourism on livelihoods assets and to compare the distinct changes in the different stages of tourism development as well as the reactions of all stakeholders involved, especially for local residents with less power and resources, in the hope of providing implications for authorities and policy makers to improve the sustainable evolution of ethnic communities.

It should be noted that this study focused on the section of livelihood assets in the sustainable livelihoods framework for ethnic tourism (Figure 2), with less emphasis on the vulnerability context and livelihood outcomes because of word limitations. Second, the study is based on three ethnic communities in different stages of tourism development during the same period. Considering the different development stages of the communities, long-term, continuous, comprehensive, and highresolution geographic information data are required to create an accurate pentagon. As it is difficult to 
comprehensively quantify all of the assets, the livelihood assets pentagons are only a rough guide to describe the distinct accesses to all assets and compare the development characteristics of the three communities. Third, it is proposed that the sustainable livelihoods framework be used for the ethnic tourism community. Further studies intend to investigate the livelihood outcomes within the three communities previously mentioned to build on the understanding and provide better guidance regarding the development of a sustainable tourism community and the livelihoods approach in these areas.

\section{Conclusions}

Tourism is strongly endorsed as a means to enhance rural, non-agricultural activities and diversify livelihoods, especially in regions with high percentages of ethnic minorities (Bhalla \& Qiu 2006; Chio 2011). This paper proposed a sustainable livelihoods framework for ethnic tourism based on tourism and livelihoods research, we added cultural capital into livelihood assets considering the character of ethnic community. This study examined three upland communities that experience the tourism impact on natural, financial, social, cultural and human aspects. The change in land use function and living environment transformation related to natural capital, the changes in the ratio of family income resources to tourism income as related to financial capital, the change in power structure and the collapse of the social and neighboring relationships related to social capital, the vanishing and commercialization of perceptible cultural materials and ethnic culture with respect to cultural capital, and the advancements in education and knowledge as related to human capital have been identified as forming new characters of these communities and creating new vulnerabilities. The livelihood pentagons were designed to indicate the evolutive characters with respect to three tourist areas, each in a different stage of development (Figure 8).

The three ethnic communities represent three separate stages in the development of tourism. Prior to tourism development, ethnic communities possess maximum access to cultural, social and natural assets with less access to financial and human assets, as evidenced by the community of Huanggang Dong. Such communities, however, can experience relatively balanced access to all livelihood assets, even when undergoing ethnic tourism development, as in the case of the community of Basha $\mathrm{Hmu}$. If tourism-related activities develop too rapidly, it will result in creating a modern town, such as in Xijiang Hmu community, which offers maximum access to human and financial assets and far less access to natural, social and cultural assets. The higher the tourism level, the less likely households are to maintain their traditional livelihoods. While this survey indicates that spectacular terraces (89.3\%), ethnic festivals (86.2\%), ethnic clothes (83.3\%), ethnic performances (84.1\%) and ethnic architecture $(85.7 \%)$ are what tourists prefer, it is these very assets, which are derived from traditional livelihoods that are changing and collapsing under the background of tourism development. The economic benefits and advanced knowledge of financial and human assets have been identified and intensely examined (Simpson 2007; Lapeyre 2010). The degradation of traditional livelihoods and the ensuing problems along with the development and integration of tourism livelihood approaches, such as the transformation of the natural landscape, the change of the power structure and the commercialization of ethnic culture in social, cultural and natural assets, influence and even stifle the balance between sustainable tourism livelihood and the preservation of rurality and ethnic culture, which could result in different livelihood outcomes and evolutive characters.

\section{Acknowledgements}

The author thanks all of the local residents and state officials with whom we talked. In addition, the author gives special thanks to Professor Sarah Turner at McGill University for her inspiration and guidance.

This work was supported by the National Natural Science Foundation of China (Grant No. 41361033). 


\section{References}

Anup KC, Resham BTP (2014) Tourism and its impact on livelihood in Manaslu conservation area, Nepal. Environment, Development and Sustainability 16(5): 1053-1063. DOI: 10.1007/s10668-013-9512-7

Ashley C (2000) The impacts of tourism on rural livelihoods in Namibia's experience. Overseas Development Institute, London, UK.

Bhalla AS, Qiu SF (2006) Poverty and inequality among Chinese minorities. Routledge, London, UK.

Bruner, EM (2005) Culture on Tour. University of Chicago Press, Chicago, USA.

Chan KW (2012) Migration and development in China: Trends, geography and current issues. Migration and Development 1(2): 187-205. DOI:10.1080/21632324.2012.739316

Chio J (2011) Leave the fields without leaving the countryside: modernity and mobility in rural, ethnic China. Identities: Global Studies in Culture and Power 18(6): 551-575. DOI: 10.1080/1070289X.2011.672858

Chow C (2005) Cultural diversity and tourism development in Yunnan Province, China. Geography 90(3): 294-303.

Cohen E (1988) Authenticity and commoditization in tourism. Annals of Tourism Research 15(3):371-386.

DOI: $10.1016 / 0160-7383(88) 90028-\mathrm{X}$

Cohen E, Avieli N (2004) Food in tourism: attraction and impediment. Annals of Tourism Research 31(4): 755-778. DOI:10.1016/j.annals.2004.02.003

Cui HY (2009) Human and paddy land: A research on traditional livelihood of Dong ethnic group in Huanggang Village, Liping County, Guizhou Province, China. Kunming: Yunnan People's Publishing House, Kunming, China. (In Chinese)

DfID (2002) Sustainable livelihood guidance sheets: Department for international department. Great Britain: Eldis Document Store, London, UK.

Donaldson J (2007) Tourism, development and poverty reduction in Guizhou and Yunnan. The China Quarterly 190: 333-351. DOI: 10.1017/So305741007001221

Ellis F (2000) Rural livelihoods and diversity in developing countries. Oxford University Press, New York, NY, USA. pp 327.

Garcia R, Canoves G, Valdovinos N (1995) Farm tourism, gender and environment in Spain. Annals of Tourism Research 22(2): 267-282. DOI: 10.1016/0160-7383(94) 00096-4

Gong R (2011) Tourism anthropology tutorial. Tourism Education Press, Beijing, China. p 130. (In Chinese)

Hall CM, Page SJ (2006) The geography of tourism and recreation: environment, place and space. Routledge, London, UK.

Ho P (2001) Who owns China's land? Policies, property rights and deliberate institutional ambiguity. The China Quarterly 166: 394-421. DOI: 10.1017/Sooo9443901000195

Lapeyre R (2010) Community-based tourism as a sustainable solution to maximize impacts locally? The Tsiseb Conservancy case, Namibia. Development Southern Africa 27(5): 757-772. DOI: $10.1080 / 0376835$ X.2010.522837

Lemoine J (2008) To tell the truth. Hmong Studies Journal 9: 129.

Leon YM (2007) The impact of tourism on rural livelihoods in the Dominican Republic's coastal areas. Journal of Development Studies 43(2): 340-359. DOI: 10.1080/ 00220380601125214

Li YJ, Turner S, Cui HY (2016) Confrontations and concessions: an everyday politics of tourism in three ethnic minority villages, Guizhou Province, China. Journal of Tourism and Cultural Change 14(1):45-61. DOI: 10.1080/14766825.2015. 1011162

Li L, Wu D, Zeng L, et al. (2013) Xijiang Miao village: its future.
China's Ethnic Groups 3: 36-43. (In Chinese)

Liu W, Jiang J (2011) The research framework for the impact of tourism development on the society and culture of a rural ethnic communities. Economic Geography 31(6): 1025-1030. (In Chinese)

Lin LF, Yang B (2007) Discussion on distortion and protection of the ethnic culture in the ethnic tourism development. Guizhou Ethnic Studies 27(5): 80-85. (In Chinese)

Luo KL, Wang X (2008) On the value of the Dong folk wisdom to maintain regional ecological security. Study of Ethnics in Guangxi 4: 88-93. (In Chinese)

Ma XJ (2000) On developing national tourism in the western regions and the preservation of national culture. Tourism Tribune 5: 50-54. (In Chinese)

MacCannell D (1973). Staged authenticity: arrangements of social space in tourist settings. American Journal of Sociology 79(3): 589-603.

Mahony K, Zyl JV (2002) The impacts of tourism investment on rural communities: three case studies in South Africa. Development Southern Africa 19(1): 83-103. DOI: 10.1080/ O3768350220123891

Matthew JW, Harold JG (2000) Local economic impacts of dragon tourism in Indonesia. Annals of Tourism Research 27(3): 559-576. DOI: 10.1016/So160-7383(99)ooo88-2

Mbaiwa JE (2011) Changes on traditional livelihood activities and lifestyles caused by tourism development in the Okavango Delta, Botswana. Tourism Management 32(5): 1050-1060. DOI: 10.1016/j.tourman.2010.09.002

Mbaiwa JE, Sakuze LK (2009) Cultural tourism and livelihood diversification: The case of Gcwihaba Caves and XaiXai village in the Okavango Delta, Botswana. Journal of Tourism and Cultural Change 7(1): 61-75. DOI: 10.1080/ 14766820902829551

Morse S, McNamara N (2013) Sustainable livelihood approach: a critique of theory and practice. Springer, Dordrecht, the Netherlands. pp: 15-60.

Nunez TA (1963) Tourism, tradition, and acculturation: Weekendismo in a Mexican village. Ethnology 2(3): 347-352.

Oakes T (1992) Cultural geography and Chinese ethnic tourism. Journal of Cultural Geography 12(2): 2-17. DOI: 10.1080/ o8873639209478405

Oakes T (1997) Ethnic tourism in rural Guizhou: sense of place and the commerce of authenticity. In: Picard M and Wood R (Eds.), Tourism, Ethnicity, and the State in Asian and Pacific Societies. University of Hawaii Press, Honolulu, HI, USA. pp: 35-70.

Ogutu ZA (2002) The impact of ecotourism on livelihood and natural resource management in Eselenkei, AmboseIi ecosystem, Kenya. Land Degradation \& development 13(3): 251-256. DOI: $10.1002 / \mathrm{ldr} .502$

Scoones I (1998) Sustainable rural livelihoods: A framework for analysis. Institute of Development Studies, Brighton, UK.

Shen F, Hughey KFD, Simmons DG (2008) Connecting the sustainable livelihoods approach and tourism: A review of the literature. Journal of Hospitality and Tourism Management 15: 19-31. DOI: 10.1375/jhtm.15.19

Simpson B (1993) Tourism and tradition: From healing to heritage. Annals of Tourism Research 20: 164-181. DOI: 10.1016/0160-7383(93)90116-K

Simpson CM (2009) An integrated approach to assess the impacts of tourism on community development and sustainable livelihoods. Community Development Journal 44(2): 186-208. DOI: $10.1093 / \mathrm{cdj} / \mathrm{bsmo} 48$

Smith V (1977) Hosts and guests: The anthropology of tourism. University of Pennsylvania Press, Philadelphia, PA, USA.

Stanisaw O (1991) Ethnic tourism: Focus on Poland. Tourism Management 12(2): 125-131. DOI: 10.1016/0261-5177(91) 90067-4 
Susan RP (1995) Ethnic tourism and nationalism in Wales. Annals of Tourism Research 22(1): 35-52. DOI: 10.1016/ 0160-7383(94)00068-4

Tao T, Wall G (2009) Tourism as a sustainable livelihood strategy. Tourism Management 30(1): 90-98. DOI: 10.1016/j. tourman.2008.03.009

Urry J (2002) The Tourist Gaze. 2nd edition. Sage Publications, London, UK

Wang DG, Wang JL, Chen T, et al. (2011) Influence model and mechanism of the rural residents for tourism support: A comparison of rural destinations of Suzhou in different life cycle stages. Acta Geographica Sinica 66(10): 1413-1426. (In Chinese)

Wu QF (2013) Qiang village tourism elite growth and national cultural identity: A case study of Long Xiao-qiong in Taoping Qiang stockade village, Li county. Tourism Research 5(3): 2932. (In Chinese)

Wood RE (1985) Ethnic tourism, the state and cultural change in Southeast Asia. Annals of Tourism Research 11(3): 353-374 DOI: 10.1016/0160-7383(84)90027-6

Xi JC, Zhao MF, Ge QS (2011) The micro-scale analysis of rural settlement land use pattern: A case study of Gouge Village of Yesanpo scenic area in Hebei Province. Acta Geographica Sinica 66(12): 1707-1717. (In Chinese)

Xi JC, Zhao MF, Ge QS, et al. (2014) Changes in land use of a village driven by over 25 years of tourism: The case of Gougezhuang village, China. Land Use Policy 40: 119-130. DOI: 10.1016/j.landusepol.2013.11.014

Xi JC, Wang XG, Kong QQ, Zhang N (2015) Spatial morphology evolution of rural settlements induced by tourism: A comparative study of three villages in Yesanpo tourism area, China. Journal of Mountain Science 25(4): 497-511. DOI: 10.1007/s11442-015-1182-y

Xia ZQ (1990) 'Gushe' and 'Yilang' study of Miao minority. Guizhou Social Sciences 10: 6-12. (In Chinese)

Xiao XH (2010) Ecological strategy research on agricultural industrial structure upgrade in minority area: Case study of southeast Guizhou Miao and Dong minority Autonomous district. Guizhou Ethnic Studies 31(4): 100-105. (In Chinese)

Xiong CM, Yang LZ (2010) The evaluation of ecological sustainability in Qiandongnan Miao and Dong Autonomous Region. Chinese Journal of Soil Science 41(1): 179-184. (In Chinese)

Ying TY, Zhou YG (2007) Community, governments and external capitals in China's rural cultural tourism: A comparative study of two adjacent villages. Tourism Management 28(1): 96-107. DOI: 10.1016/j.tourman.2005. 12.025

Yang L (2006) Ethnic tourism development: Chinese government perspectives. Annals of Tourism Research 35(3): 751-771. DOI: 10.1016/j.annals.2008.06.005

Yang L, Wall G, Smith SLJ (2008) Ethnic tourism development. Annals of Tourism Research 35(3): 751-771. DOI: 10.1016/j. annals.2008.06.005

Yang L (2011) Ethnic tourism and cultural representation. Annals of Tourism Research 38(2): 561-585. DOI: $10.1016 / \mathrm{j}$ annals.2010.10.009

Zhou SZ, Guo FL (2007) Transition of 'Common Law' of Dong minority: A case study of constitution 'Kuan Yue'. Northern Legal Science 5: 115-121. (In Chinese) 